\title{
Intralesional Vinblastine Regimen
}

National Cancer Institute

\section{Source}

National Cancer Institute. Intralesional Vinblastine Regimen. NCI Thesaurus. Code

C160065.

A chemotherapy regimen consisting of intralesional vinblastine that may be used in the treatment of AIDS-related Kaposi sarcoma and desmoid tumors. 